The International Journal of the First Year in Higher Education ISSN: 1838-2959

Volume 3, Issue 2, pp. 45-58

August 2012

\title{
First year mathematics at a regional university: Does it cater to student diversity?
}

\author{
Robert Whannell and Bill Allen \\ University of the Sunshine Coast, Sunshine Coast, Australia
}

\begin{abstract}
This study examines the academic performance of students in a first year undergraduate mathematics course at a regional university. A custom designed questionnaire which assessed study behaviours, staff support and peer and family relationships and the levels of mathematics efficacy and anxiety was completed by 162 students. The study established a wide range of mathematical efficacy based upon the number and type of mathematics courses completed at the secondary level of education and identifies this as the primary factor in student failure in the course. The need for institutions to acknowledge the diversity of student preparedness in mathematics at the first year undergraduate level and respond through the use of academic staff with appropriate educational training and a caring and supportive teaching pedagogy is described. The capacity of a single one-size-fits-all mathematics course in the first semester of undergraduate study to meet the needs of all students is discussed.
\end{abstract}

Please cite this article as:

Whannell, R \& Allen, B. (2012) First year mathematics at a regional university: Does it cater for student diversity? The International Journal of the First Year in Higher Education, 3(2). 45-58. doi: 10.5204 /intifyhe.v3i2.125

This article has been peer reviewed and accepted for publication in Int J FYHE. Please see the Editorial Policies under the 'About' section of the Journal website for further information.

(C) Copyright of articles is retained by author/s. As an open access journal, articles are free to use, with proper attribution, in educational and other non-commercial settings. ISSN: 1838-2959 


\section{Introduction}

The challenges experienced by students as they transition into the first year of study in Australian universities has been extensively researched and received particular attention in the Bradley Report into higher education (Bradley, Noonan, Nugent, \& Scales, 2008). The particular challenges associated with the study of first year undergraduate mathematics has been described both in Australia and internationally (e.g. Hourigan \& O'Donoghue, 2007; Kajander \& Lovric, 2005; Keeves, 1973).

The regional university where this study was completed offers one first year undergraduate course in mathematics. Each cohort comprises about 250 students and in recent years has recorded a failure rate of approximately $45 \%$. The course is compulsory in many undergraduate programs and is a pre-requisite to allow many students to be able to progress in their program of study. The course is only offered in the first semester each year. Failure to pass the course imposes a substantial penalty on students who must wait until the next year before the course is able to be attempted again and who must also be able to continue their study in the face of a course failure, which for many has occurred in the first semester of their tertiary education. Some students with a low level of preparedness who encounter such a failure have previously been demonstrated to completely disengage with mathematics at the tertiary level (Varsavsky, 2010).

The purpose of this quantitative study was to examine the student experience in a first year undergraduate mathematics course and to determine if the availability of a single first year mathematics course required to serve all students was suitable and gave students the best opportunity for success in their university study. The paper also explores the influence that one course may have on the overall attrition rate of the university.

\section{Theoretical background}

An Australian longitudinal trend study (Krause, Hartley, James, \& McInnis, 2005) of the first year transition into university identified a number of generic factors which were hypothesised to influence the quality of the outcomes achieved, including the amount of time spent on campus, whether studying full or part time and gender. Factors external to the university, including the number of hours of paid work completed and the quality of family support, were also described. A study at the University of Victoria (Cao \& Gabb, 2006) identified gender, age, enrolment status, socio-economic status and the quality of academic achievement as being involved in the first year attrition phenomenon.

A number of factors have been identified as being relevant to the quality of outcomes in introductory university mathematics courses, including the quality of previous mathematics achievement and the amount of secondary school mathematics completed (Peard, 2004). The factors identified depend on whether the source is the teaching staff or students (Anthony, 2000) where teaching staff identify student-oriented factors such as the amount of study, insufficient mathematical background and lack of previous performance and lack of effort and motivation. Students orient their comments more towards aspects relating to the delivery of content, academic support and teaching pedagogy. The 
importance of an appropriate mathematics background is identified by other researchers (Hourigan \& O'Donoghue, 2007; Kajander \& Lovric, 2005; Peard, 2004).

Students' attitudes towards the study of mathematics have also been demonstrated to influence the outcomes achieved (Hackett \& Betz, 1989; McLeod, 1994; Reyes, 1984) and have continued to be the focus of much research relating to mathematics education (Leder \& Grootenboer, 2005). In particular, the problem solving which is inherent in the study of mathematics has been demonstrated to strongly influence students' attitudes, both positive and negative (Debellis \& Goldin, 2006; Hannula, 2002). Liljedahl (2005) examined the influence of what he described as the aha experience in undergraduate mathematics students and established that such experiences have "a transformative effect on 'resistant' students' affective domains creating positive beliefs and attitudes about mathematics as well as their ability to do mathematics" (p. 219).

Supportive and higher educated families have been identified as playing a role in improving the outcomes for students studying mathematics (Ercikan, McCreith, \& Lapointe, 2005). A similar positive effect has been identified where supportive academic staff (Midgley, Feldlaufer, \& Eccles, 1989) and peer relationships (Eccles \& Jacobs, 1986) have been established. A positive staff-student relationship has also been demonstrated to reduce the level of anxiety experienced by students when undertaking mathematics courses (Clute, 1984), particularly where the teacher takes on a counselling role which targets the students' anxiety (Furner \& Duffy, 2002). The primary predictors of anxiety in mathematics students have been shown to include the students' ability perceptions and performance expectancies (Meece, Wigfield, \& Eccles, 1990) while females and older students have been demonstrated to experience higher mathematics anxiety (Balog lu \& Koçak, 2006). Higher levels of mathematics anxiety have also been identified in students with lower levels of existing mathematical knowledge (Cates \& Rhymer, 2003) and have been associated with lower levels of achievement (Ma, 1999). Norwood (1994) suggested that "students with high mathematics anxiety are more comfortable with a highly structured, algorithmic course than a less structured, conceptual course" (p. 248) such as that which would be encountered at the tertiary level of education.

\section{Secondary school mathematics study}

In Queensland, where this study was conducted, there are three different mathematics courses studied in years 11 and 12: Mathematics A, Mathematics B and Mathematics C. Students intending to study mathematics at tertiary level are recommended to study Mathematics B. Those who will be completing courses which have a very high mathematics requirement, for example engineering, are also recommended to study Mathematics $\mathrm{C}$ in addition to Mathematics $B$, although most Australian universities do not require this course as a pre-requisite to gain access. The major areas of study which are included in Mathematics B and C which are not addressed in Mathematics $A$ are algebra, trigonometry and calculus. Students who complete Mathematics A normally do not complete Mathematics B or C. While student diversity is often associated with students from nontraditional backgrounds, this secondary 
school context gives rise to a wide diversity of mathematics preparation in students entering tertiary study direct from school.

The research questions which directed the research project were What factors influence the achievement and/or failure of students in first year mathematics? and What strategies are available to cater for student diversity and thereby reduce course failure in first year mathematics?

\section{Method}

A custom-designed questionnaire was developed commencing with an introductory section which obtained demographic and study behaviour information. The result from the first online assessment task completed in week 3 of the semester and the final overall result were included. The week 3 task comprised 15 multiple-choice items targeting basic algebra skills which were typical of what would be expected at year 10 and 11 at secondary school.

Participants reported the mathematics courses which were being completed at the end of secondary school. To differentiate between participants based upon the amount of mathematics preparation at secondary level, participants were grouped into

- Other;

- Year 10;

- Mathematics A;

- Mathematics B only; and

- those who had completed both Mathematics B and C.

Thus, the level of mathematics preparedness would be expected to be highest for students who had completed both Mathematics B and C, followed by those who had completed Mathematics B only.

The second section of the questionnaire comprised a number of Likert-style items which utilised a five-point scale ranging from Strongly Disagree, scored as 1 , to Strongly Agree, scored as 5. These items were intended to be used to develop summated scales to measure constructs identified during the literature review as being relevant to the participants' performance in mathematics.

Of the 255 students enrolled in the course, the questionnaire was completed by 162 participants giving a $63.5 \%$ response rate. The questionnaire was completed in the week 3 lecture of the mathematics course. The gender composition was 101 (62.3\%) male and $61(37.7 \%)$ female with a median age of 19. This composition was representative of the cohort as a whole. A Principal Components Analysis using direct oblimin rotation and Kaiser normalisation was completed using the Likert-style items. A six factor solution was identified which accounted for $65.3 \%$ of the shared variance in the factor items. The six scales comprised a total of 31 items giving a 5.2:1 response-to-item ratio. Factors were named based upon their constituent items and are summarised in Table 1.

All items loaded on their respective factor with a minimum of .544 with all inter-item correlations for a given factor being statistically significant $(p<0.01)$. The Cronbach's alpha values indicate a high level of internal reliability for each scale.

The Staff Support scale included items which specifically targeted the mathematics support which was available from academic staff, and included items such as I discuss my mathematics problems 


\begin{tabular}{|lccc|}
\hline \multicolumn{4}{c|}{ Table 1: Questionnaire scales } \\
\hline Scale & No Items & Cronbach's Alpha & Scale Range \\
\hline Staff Support & 6 & .868 & $6-30$ \\
Family Relationships & 8 & .880 & $8-40$ \\
Peer Relationships & 4 & .842 & $4-20$ \\
Mathematics Efficacy & 6 & .877 & $6-30$ \\
Mathematics Attitude & 4 & .837 & $4-20$ \\
Mathematics Anxiety & 3 & .763 & $3-15$ \\
\hline & & & \\
\hline
\end{tabular}

with academic staff and Academic staff are supportive of my work in mathematics. The Family Relationships and Peer Relationships scales measured the wider nature of the relationships between the participant and his/her family and peers in the mathematics course and included items such as I like to get my family's point of view on things related to my university study, My family are supportive of my desire to attend university, I have positive relationships with other students in the mathematics course and I can go to other students for support in relation to my work in the mathematics course.

The Mathematics Efficacy scale measured the participants' perception of their mathematical ability and included items such as I feel that my mathematical background is sufficient to allow me to cope with university mathematics and The mathematics tutorial exercises have been easy. The Mathematics Attitude scale measured aspects of the participants' attitude towards and emotional experience of mathematics and included items such as I get a sense of satisfaction when I solve mathematics problems and $I$ consider mathematics an important aspect of my tertiary study.

Three items assessed the level of anxiety associated with the participants' study of mathematics. The items in the Mathematics Anxiety scale were I find

Table 2: Secondary school mathematics studied and course outcome

\begin{tabular}{lcccc}
\hline Secondary school mathematics & Frequency & Percent & Passed & Failed \\
\hline Other & 14 & 8.6 & $10(76.9 \%)$ & $3(23.1 \%)$ \\
Year 10 Mathematics & 11 & 6.8 & $5(45.5 \%)$ & $6(54.5 \%)$ \\
Mathematics A & 48 & 29.6 & $33(71.7 \%)$ & $13(28.3 \%)$ \\
Mathematics B Only & 56 & 34.6 & $42(75 \%)$ & $14(25 \%)$ \\
Mathematics B and C & 32 & 19.8 & $26(81.3 \%)$ & $6(18.8 \%)$ \\
Missing & 1 & .6 & & \\
\hline Total & 162 & 100.0 & $116(73.4 \%)$ & $42(26.6 \%)$ \\
\hline
\end{tabular}


mathematics a confusing area of study, I feel anxious knowing I have to go to mathematics lectures/tutorials and I find studying mathematics stressful.

\section{Results}

Participants reported the type of secondary mathematics course being studied at the time of leaving secondary school with the results shown in Table 2. The table also includes the pass/fail result for each group on the current university mathematics course.

Note that the numbers shown for Pass/Fail in each group do not total to the number who completed the questionnaire in week 3 due to some of the participants withdrawing from the course with no grade being awarded. Participants who chose the Other option included those who had attended secondary school in a different state or country and those who had been home-schooled.

A one-way ANOVA was performed on each of the summated scales and the overall course result using the type of secondary schooling as the control variable. The results are shown in Table 3. Participants categorised as Other were removed from the analysis as their secondary school backgrounds were not known. In each case outliers identified by reference to the box plot were removed from the analysis.

The analysis indicates that statistically significant differences existed for the Mathematics Efficacy, Mathematics Attitude and Mathematics Anxiety scales and for the overall result achieved for the course. It is also apparent that the level of Mathematics Efficacy is strongly negatively associated with the level of Mathematics Anxiety experienced $(r=-.706, n=$ $140, p<.001)$. The participants' sense of Mathematical Efficacy is substantially higher if Mathematics B and Mathematics C were completed. Conversely, the level of Mathematics Anxiety experienced was lower where the participants had completed these courses. The level of Mathematics Anxiety also demonstrated significant negative associations with Mathematics Attitude $(r=-.494, n=$ $142, p<.001)$ and Staff Support $(r=-.301, n=143, p<.001)$.

While there was very little difference in the overall achievement in the course between participants who completed either Mathematics A or Mathematics B only, the quality of result for those who only completed Mathematics to year 10 level is very low with a mean of only $50 \%$. The

Table 3: One-way ANOVA analysis

\begin{tabular}{|lcccccc}
\hline \multirow{2}{*}{ Scale } & \multicolumn{7}{c}{ Mean Result } & \\
\cline { 2 - 5 } & Year 10 & Maths A & Maths B & Maths B \& & F & Sig. \\
\hline Staff Support & 23.5 & 21.4 & 21.3 & 23.1 & 2.415 & .069 \\
Family Relationships & 31.4 & 33.0 & 31.9 & 32.5 & 0.515 & .673 \\
Peer Relationships & 15.2 & 15.1 & 15.4 & 15.9 & 0.752 & .523 \\
Mathematics Efficacy & 18.3 & 19.7 & 23.3 & 26.2 & 27.994 & .000 \\
Mathematics Attitude & 17.0 & 15.2 & 15.7 & 17.0 & 3.606 & .015 \\
Mathematics Anxiety & 8.3 & 8.8 & 7.2 & 5.7 & 12.752 & .000 \\
Course Result (\%) & 50.0 & 63.5 & 62.5 & 72.2 & 3.070 & .030 \\
\hline
\end{tabular}


mean result for those who completed Mathematics B and C is high at $72.2 \%$ and is significantly higher than those who did Mathematics A only (Mean Difference = $23.25, p=.025$ ).

A Kruskul-Wallis test was conducted on the number of hours of weekly study, hours of weekly paid work, the number of classes absent and the result on the first assessment task completed in week 3 of the semester to identify any significant differences based upon the type and number of secondary mathematics courses completed and are shown in Table 4. The non-parametric test was used as the datasets demonstrated extreme violation of normality.
Mathematics B and C who achieved at a substantially higher level. It should be noted that these participants report the lowest number of hours of weekly study.

A binary logistic regression analysis was also completed to identify those variables which could be used as predictors of course failure at week 3 of the semester. This would give the opportunity to identify the risk factors which could be utilised in the future to identify students at risk of course failure. The variables included in the model were those which indicated reasonable differences on the independent samples t-test and Mann-Whitney $U$ test: Mathematics Efficacy, Mathematics Anxiety and the result on the first assessment task in week 3. Cases with a Cook's influence of

Table 4: Kruskul-Wallis Tests

\begin{tabular}{|c|c|c|c|c|c|c|c|}
\hline \multirow[b]{2}{*}{ Scale } & \multicolumn{4}{|c|}{ Mean Rank } & \multirow[b]{2}{*}{$\chi^{2}$} & \multirow[b]{2}{*}{$d f$} & \multirow[b]{2}{*}{ Sig. } \\
\hline & Year 10 & Maths A & Maths B & $\begin{array}{c}\text { Maths B \& } \\
\text { C }\end{array}$ & & & \\
\hline $\begin{array}{l}\text { Hours Weekly } \\
\text { Study }\end{array}$ & 119.23 & 79.31 & 68.02 & 58.84 & 18.937 & 3 & .000 \\
\hline $\begin{array}{l}\text { Weekly Paid } \\
\text { Work }\end{array}$ & 109.86 & 70.07 & 74.79 & 61.27 & 11.727 & 3 & .008 \\
\hline Week 3 Result & 65.65 & 66.05 & 56.17 & 81.98 & 8.796 & 3 & .032 \\
\hline
\end{tabular}

It is apparent that the number of hours of study completed each week varies substantially depending on which secondary mathematics courses were completed. A particular issue which appears from this data is that the participants who completed only year 10 mathematics appear to complete a much higher number of hours of weekly work. The week 3 results demonstrate very little difference, with the exception of those participants who had completed both greater than 1 and with standardised residuals of greater than 2 were removed from the analysis as recommended by Field (2009). This resulted in 121 cases being included in the analysis. A test of the full model with all predictors against a constant-only-model was statistically reliable $\left(\chi^{2}=60.981, d f=3, n=139, p<\right.$ .001 ) indicating that the predictors reliably distinguished between the participants based upon their failure of the course. Nagelkerke's $\mathrm{R}^{2}$ value of .570 indicated a moderate relationship between the 
predictor variables and course failure while the Hosmer and Lemeshow test $\left(\chi^{2}(d f=8)=7.427, p=.491\right)$ indicated a good match between the predicted and observed probabilities. The overall prediction rate was moderate at $83.5 \%$ with $58.8 \%$ of the participants in the failure group correctly identified and $93.1 \%$ in the passing group correctly identified. According to the Wald criterion, the predictor variables which made a statistically significant contribution to the model were the level of Mathematics Efficacy $(z=8.364, p=004)$ and the result on the first assessment task $(z=22.169, p<.001)$. The variables table from the regression analysis is shown in Table 5.

The analysis at this point indicates that the different from zero $(F=35.396, p<.001)$. The variables which were found to contribute significantly to the model were Staff Relationships $(t=9.793, p<.001)$, Mathematics Anxiety $(-8.738, p<.001)$ and age $(t=-4.968, p<.001)$. The quality of Family Relationships was just outside the cut-off for significance at the 95\% confidence level. The model accounted for $59.4 \%$ of the variance in Mathematics $\left(R^{2}=.611\right.$, adjusted $\left.R^{2}=.594\right)$.

The assumptions of the regression were tested with an examination of the distribution of standardised residuals, which were observed to be very close to a normal distribution, while the plot of residuals versus predicted value indicated homogeneity of variance. The beta values

\begin{tabular}{|lcccccc|}
\hline \multicolumn{7}{c|}{ Table 5: Binary logistic regression analysis } \\
\hline Scale & B & S.E. & Wald & df & Sig. & Exp(B) \\
\hline Mathematics Efficacy & -.285 & .098 & 8.364 & 1 & .004 & .752 \\
Mathematics Anxiety & -.131 & .130 & 1.004 & 1 & .316 & .878 \\
Week 3 Result & -.979 & .208 & 22.169 & 1 & .000 & .376 \\
Constant & 17.274 & 4.388 & 15.499 & 1 & .000 & $3.178 \mathrm{E} 7$ \\
\hline
\end{tabular}

primary indicators at week 3 of the semester of student failure in the course are the level of Mathematics Efficacy and the result on the first assessment task. A linear regression was then performed to determine the factors which were associated with the participants' Mathematical Efficacy. Table 6 shows the Pearson's $r$ correlations for Mathematics Efficacy.

A standard linear regression was performed using all variables which were significantly correlated with Mathematics Efficacy. The multiple correlation coefficient $(R=.782)$ was significantly indicate that the major positive influence on mathematical efficacy is the quality of Staff Support provided to the participants ( $\beta=.154)$, while the major negative influence is the amount of anxiety associated with the study of mathematics ( $\beta=-.561)$.

\section{Discussion}

The data analysis has demonstrated the diverse nature of the mathematics preparedness and efficacy of the participants. While only $18.8 \%$ of participants who had completed Mathematics B and C failed the course, 
Table 6: Pearson's r correlation coefficients - Mathematics Efficacy

\begin{tabular}{|c|c|c|c|c|c|c|c|c|c|}
\hline & & $\begin{array}{c}\text { Staff } \\
\text { Support }\end{array}$ & $\begin{array}{c}\text { Family } \\
\text { Relationships }\end{array}$ & $\begin{array}{c}\text { Peer } \\
\text { Relationships }\end{array}$ & $\begin{array}{c}\text { Mathematics } \\
\text { Attitude }\end{array}$ & $\begin{array}{c}\text { Mathematics } \\
\text { Anxiety }\end{array}$ & $\begin{array}{l}\text { Hours } \\
\text { Study }\end{array}$ & $\begin{array}{l}\text { Classes } \\
\text { Missed }\end{array}$ & Age \\
\hline \multirow[t]{3}{*}{$\begin{array}{l}\text { Mathematics } \\
\text { Efficacy }\end{array}$} & Correlation & $.376^{* *}$ & $.294^{* *}$ & $.319^{* *}$ & $.434^{* *}$ & $-.706^{* *}$ & -.080 & -.038 & $.376^{* *}$ \\
\hline & Sig. & .000 & .000 & .000 & .000 & .000 & .345 & .652 & .000 \\
\hline & $\mathrm{N}$ & 144 & 142 & 144 & 144 & 144 & 143 & 143 & 144 \\
\hline
\end{tabular}

**. Correlation is significant at the 0.01 level (2-tailed).

$54.5 \%$ of those who had only completed mathematics to year 10 failed in spite of a significantly higher number of hours of weekly study being completed. A similar pattern is seen in respect of the level of perceived Mathematics Efficacy where participants who had completed Mathematics $\mathrm{B}$ and $\mathrm{C}$ demonstrated substantially higher results. An associated issue for the participants who entered the course with a low level of Mathematics Efficacy was significantly higher levels of Mathematics Anxiety. The logistic regression analysis identified the primary risk factors for course failure at week 3 of the semester as the participants' level of Mathematical Efficacy and their result on the first assessment task. Considering that the first assessment task targeted mathematics only at the years 10 and 11 level, it is concluded that course failure is largely dependent upon the level of preparedness gained through mathematical exposure at the secondary level of education. This supports the findings in previous studies (Hourigan \& O'Donoghue, 2007; Kajander \& Lovric, 2005; Peard, 2004). The lack of preparedness and Mathematical Efficacy of the participants was also strongly associated with a high level of Mathematical Anxiety which previous studies have shown to influence achievement negatively (Ma, 1999; Meece et al., 1990).

There are two contrary approaches which are available when interpreting these findings. The first, and perhaps more common, is to describe the diverse nature of the student cohort in terms of the lack of mathematics preparedness of students (Varsavsky, 2010) and the falling standards in mathematics preparation provided by secondary schools (James, Montelle, \& Williams, 2008; Otung, 2001; Taylor \& Morgan, 1999). When it is considered that the course completed is essentially a consolidation of year 11 and 12 mathematics, this view appears to be supported due to the high percentage of participants who failed the course who completed Mathematics B (25\%) or Mathematics B and C (18.8\%). The solution when this approach is adopted is to develop strategies which aim to improve the preparedness of students. One strategy to improve preparedness and provide additional support and used at the institution where this study was conducted, is through the provision of a tertiary enabling course in mathematics. This course, which addresses the same content and does not provide credit towards a degree, has been available for a number of years and is normally done by students in the same semester. This 
strategy, to date, does not appear to have made a substantial impact on the failure rate. The findings suggest that where such a course is completed concurrently, its capacity to improve preparedness and Mathematical Efficacy and reduce anxiety is limited. An alternative option would be the completion of such a course prior to commencement.

A second approach is to address the issue from an institutional perspective where the manner in which the course is presented and the personnel involved are examined. The multiple regression demonstrated that the factors significantly associated with the level of the participants' Mathematical Efficacy were the nature of the relationships with academic staff and family and the level of Mathematics Anxiety. This indicates that one method of improving the student's Mathematical Efficacy, and in turn reducing the potential for course failure, is through the provision of a supportive student-teacher relationship which specifically targets the issue of mathematical anxiety (Furner \& Duffy, 2002). It will be remembered that the level of Mathematics Anxiety was negatively associated with Staff Support $(r=-.301, n=143, p<.001) \quad$ giving additional support for this stance. Mathematics Anxiety was also negatively associated with Mathematical Attitude $(r=-.494, n=142, p<.001) . \quad$ This study supports the existing literature (Clute, 1984; Furner \& Duffy, 2002; Midgley, et al., 1989) which identifies a role for academic staff in improving the outcomes in mathematics education through the use of appropriate social and supportive teaching pedagogies. The choice of academic staff in introductory tertiary mathematics courses who utilise social and caring teaching pedagogies directed at improving students' perceptions of their mathematical efficacy and reducing anxiety would also assist in reducing failure in these courses.

As described, the regional university where this study was conducted only provides one first year mathematics course which is completed by all students who require mathematics in their degree program. This requires that the course be presented at a level to support the high level needs of students undertaking programs such as engineering, and includes topics such as matrices and vectors, while still being presented at a sufficiently low level so that students with limited background and preparedness are able to cope with the content. When the diverse nature of the student cohort is considered, it seems that a one-size-fits-all approach of offering only one course may not be appropriate. High failure levels in a compulsory first year course which serves a number of degree programs will also have a detrimental effect across the wider institution. It is proposed that, from an institutional perspective, the opportunity would exist to offer two strands of mathematics at first year level to cater to the diverse needs of the student cohort. It is also proposed that offering the course two semesters per year would also reduce the seriousness of course failure.

\section{Conclusion}

This study has revealed factors that are important to reducing the failure rate in an introductory mathematics course. But it should not be considered in isolation. Because of the importance of this course as a pre-requisite for later courses and its completion in the first semester of study for many students, the impact of its failure on wider institutional attrition cannot be ignored. In a small regional university, achieving the balance between providing an appropriate introduction to tertiary 
mathematics for students with a wide range of mathematical preparedness and providing the staff and financial resources required to do so will not be a simple task. However, in the post-Bradley era (Bradley et al., 2008), where universities respond by continuing to widen access to tertiary education to non-traditional students, they must accept and meet the responsibility to provide an educational experience which recognises and caters for the students' identified lack of preparedness. This responsibility is further heightened by the current attention being given to problems of improving the uptake and success of students in the study of Science, Technology, Engineering and Mathematics (STEM) by tertiary institutions (Universities Australia, 2012) and the Australian Government (Office of the Chief Scientist, 2012). Tinto's (2008) view that access without support is not opportunity also extends to adapting the manner in which existing programs are offered, not just providing additional support through formal student support services and enabling courses.

\section{References}

Anthony, G. (2000). Factors influencing first-year students success in mathematics. International Journal of Mathematical Education in Science and Technology, 31(1), 3-14. doi: 10.1080/002073900287336.

Balog lu, M., \& Koçak, R. (2006). A multivariate investigation of the differences in mathematics anxiety. Personality and individual differences, 40(7), 1325-1335. doi: 10.1016/j.paid.2005.10.009

Bradley, D., Noonan, P., Nugent, H., \& Scales, B. (2008). A review of Australian higher education. Retrieved from www.deewr.gov.au/HigherEducation/Revi ew/Documents/PDF/Higher\%20Education \%20Review_one\%20document_02.pdf

Cao, Z., \& Gabb, R. (2006). Student attrition at a new generation university. Postcompulsory
Education Centre, Victoria University, Melbourne, Australia.

Cates, G., \& Rhymer, K. (2003). Examining the relationship between mathematics anxiety and mathematics performance: An instructional hierarchy perspective. Journal of Behavioral Education, 12(1), 23-34. doi: 10.1023/A:1022318321416

Clute, P. (1984). Mathematics anxiety, instructional method, and achievement in a survey course in college mathematics. Journal for Research in Mathematics Education, 15(1), 50-58. doi: 10.2307/748987.

Debellis, V., \& Goldin, G. (2006). Affect and metaaffect in mathematical problem solving: A representational perspective. Educational Studies in Mathematics, 63(2), 131-147. doi: 110.1007/s10649-10006-19026-10644.

Eccles, J., \& Jacobs, J. (1986). Social forces shape math attitudes and performance. Signs, 11(2), 367-380. doi: 310.1007/s10649-1000619026-10644.

Ercikan, K., McCreith, T., \& Lapointe, V. (2005). Factors associated with mathematics achievement and participation in advanced mathematics courses: An examination of gender differences from an international perspective. School Science and Mathematics, 105(1), 5-14. doi: 10.1111/j.1949-8594.2005.tb18031.x.

Field, A. (2009). Discovering statistics using SPSS. London: SAGE Publications Ltd.

Furner, J., \& Duffy, M. (2002). Equity for all students in the new millenium: Disabling math anxiety. Intervention in School and Clinic, 38(2), 6774. doi: 10.1177/10534512020380020101.

Hackett, G., \& Betz, N. (1989). An exploration of the mathematics self-efficacy/mathematics performance correspondence. Journal for Research in Mathematics Education, 20(3), 261-273. doi: 210.2307/749515.

Hannula, M. (2002). Attitude towards mathematics: Emotions, expectations and values. Educational Studies in Mathematics, 49(1), 25-46. doi: 10.1023/A:1016048823497

Hourigan, M., \& O'Donoghue, J. (2007). Mathematical under-preparedness: The influence of the pre-tertiary mathematics experience on students' ability to make a successful transition to tertiary level mathematics courses in Ireland. International Journal of Mathematical Education in Science and Technology, 38(4), 461-476. doi: $410.1080 / 00207390601129279$. 
James, A., Montelle, C., \& Williams, P. (2008). From lessons to lectures: NCEA mathematics results and first-year mathematics performance. International Journal of Mathematical Education in Science and Technology, 39(8), 1037-1050. doi: $1010.1080 / 00207390802136552$.

Kajander, A., \& Lovric, M. (2005). Transition from secondary to tertiary mathematics: McMaster University experience. International Journal of Mathematical Education in Science and Technology, 36(2), 149-160. doi: $110.1080 / 00207340412317040$.

Keeves, J. (1973). Differences between the sexes in mathematics and science courses. International Review of Education, 19(1), 47-63. doi: 10.1007/BF00597775.

Krause, K., Hartley, R., James, R., \& McInnis, C. (2005). The first year experience in Australian universities: Findings from a decade of national studies. Canberra, Australia: Department of Education, Science and Training.

Leder, G., \& Grootenboer, P. (2005). Affect and mathematics education. Mathematics Education Research Journal, 17(2), 1-8. doi: 10.1007/BF03217413.

Liljedahl, P. (2005). Mathematical discovery and affect: The effect of AHA! Experiences on undergraduate mathematics students. Science and Technology, 36(2-3), 219-234. doi: 10.1080/00207390412331316997

Ma, X. (1999). A meta-analysis of the relationship between anxiety toward mathematics and achievement in mathematics. Journal for Research in Mathematics Education, 30(5), 520-540. doi: 510.2307/749772.

McLeod, D. (1994). Research on affect and mathematics learning in the JRME: 1970 to the present. Journal for Research in Mathematics Education, 25(6), 637-647. doi: $610.2307 / 749576$.

Meece, J., Wigfield, A., \& Eccles, J. (1990). Predictors of math anxiety and its influence on young adolescents' course enrollment intentions and performance in mathematics. Journal of Educational Psychology, 82(1), 60-70. doi: 10.1037//0022-0663.1082.1031.1060.

Midgley, C., Feldlaufer, H., \& Eccles, J. (1989). Student/teacher relations and attitudes toward mathematics before and after the transition to junior high school. Child Development, 60(4), 981-992. doi: $910.2307 / 1131038$.
Norwood, K. (1994). The effect of instructional approach on mathematics anxiety and achievement. School Science and Mathematics, 94(5), 248-254. doi: 210.1111/j.1949-8594.1994.tb15665.x.

Office of the Chief Scientist. (2012). Health of Australian science. Canberra, Australia: Australian Government. Retrieved from http://www.chiefscientist.gov.au/wpcontent/uploads/Report-for-web.pdf

Otung, I. (2001). Reassessing the mathematics content of engineering education. Engineering Science and Education Journal, 10(4), 130138. doi: 110.1049 /esej:20010401.

Peard, R. (2004, June). School mathematical achievement as a predictor of success in a first year university mathematics foundations unit. Paper presented at the 27th Annual Conference of the Mathematics Education Research Group of Australiasia, Townsville, Australia.

Reyes, L. (1984). Affective variables and mathematics education. The Elementary School Journal, 84(5), 558-581. doi: 510.1086/461384.

Taylor, J., \& Morgan, M. (1999). Mathematics support program for commencing engineering students between 1990 and 1996: An Australian case study. International Journal of Engineering Education, 15(6), 486-492.

Tinto, V. (2008, November). Access without support is not opportunity. Paper presented at the 36th Annual Institute for Chief Academic Officers, The Council of Independent Colleges. Seattle, Washington.

Universities Australia. (2012). STEM and non-STEM first year students. Retrieved from http://www.universitiesaustralia.edu.au/p age/submissions---reports/reviews-andinquiries/stem-and-non-stem-first-yearstudents- $/$

Varsavsky, C. (2010). Chances of success in and engagement with mathematics for students who enter university with a weak mathematics background. International Journal of Mathematical Education in Science and Technology, 41(8), 1037-1049. doi:

1010.1080/0020739X.0022010.0493238. 
Whannell \& Allen

The International Journal of the First Year in Higher Education, 3(2) August, 2012 | 57 
First year mathematics at a regional university: Does it cater to student diversity?

58 The International Journal of the First Year in Higher Education, 3(2) August, 2012 